UDK: 81'243:316.72

\title{
- KULTURA I UČENJE STRANIH JEZIKA
}

\author{
MARIN MARKOŠ ${ }^{1}$ \\ Univerzitet odbrane, \\ Vojna akademija, Katedra za strane jezike, \\ Beograd, Srbija
}

U radu se ukazuje na važnost izučavanja odnosa jezika i kulture $u$ nastavi stranog jezika. Na primerima iz više jezika pokazuju se razlike u konceptualizaciji i realizaciji jezičkih kategorija i ukazuje se na međuzavisnost jezičkih jedinica i kulturoloških modela. Kao što postoji čvrsta veza između jedne kulture i jezika, tako postoje i razlike između jezika, odnosno između kultura. Učenje stranog jezika je stoga istovremeno i učenje tih kulturoloških razlika i učenje određenih komunikativnih modela ponašanja. Učenjem jezičkih, kulturoloških i komunikativnih pravila stiče se tzv. interkulturalna kompetencija. Uz odgovarajući pedagoški rad, polaznici kurseva stranog jezika treba da budu praktično osposobljeni za komuniciranje u multilingvalnom i multikulturalnom okruženju.

Ključne reči: kultura, jezik, transfer, ponašanje, praksa, komunikacija, interkulturalna kompetencija.

\section{UVOD}

Priroda i intenzitet međujezičkih kontakata promenili su smisao i način učenja stranog jezika. Istovremena globalizacija i lokalizacija u ekonomiji, integracije i sukobi u politici, informatička revolucija, mobilnost sve većeg broja ljudi i stvaranje mreža i neformalnih zajednica, stvarnih i virtuelnih, relativizovali su političke, lingvističke i kulturalne granice.

No, u komunikaciji, da bi se ostvarili svi ciljevi - lični, organizacioni ili nacionalni, veoma je važno razumevanje konteksta upotrebe jezika. Tako je ekonomsko-politička situacija u svetu doprinela da se strani jezici mnogo više izučavaju nego što je to bilo ranije, pre sedamdesetih godina prošlog veka. U izučavanju i upotrebi jezika, pored ekonomsko-političke situacije, važan je i socio-kulturni kontekst. Redefinišući tumačenja konteksta, jezičke relativnosti, sociokulturalnih faktora u kognitivnom

1 Kontakt podaci (Email): marinmarkos@yahoo.com 
razvoju, kompetencijeidiskursa, moderna naukase ponovo baviodnosomjezika, mišljenja i kulture i posledica koje takav odnos ima za učenje/usvajanje drugog/stranog jezika (Kramsch 2004). Kako se poznavanje samo jezičkog sistema pokazalo kao nedostatno za efikasnu komunikaciju u multikulturalnom svetu intenzivnih kontakata, uveden je konstrukt interkulturalne kompetencije. Taj koncept primarno vezan za znanje i učenje jezika, treba da ujedini širok spektar znanja, veština i stavova pojedinca ili zajednice kako bi mogli da pronađu uspešan odgovor na zahteve kompleksnog okruženja.

\section{KULTURA U JEZIKU}

U tom kompleksnom okruženju kultura i jezik su tako povezani da je teško povući jasnu granicu u izučavanju jednog ili drugog. U osnovi kulture, koju antropolozi definišu kao „obrazac značenja pretočenih u simbole, sistem nasleđenih koncepcija ... putem kojih ljudi komuniciraju i razvijaju znanje i stavove“ (Geertz 1973), odnosno „kolektivno programiranje uma koje članove jedne grupe razlikuje od drugih" (Hofstede et al. 2010: 6), možemo da prepoznamo jezik kao sistem simbola koji u datoj zajednici prenosi zajedničke koncepte i obezbeđuje stepen uniformnosti potreban za održanje zajednice. Jezik je istovremeno deo kulture i medij kroz koji se ona izražava. Ako kultura postavlja okvire za mišljenje i ponašanje, kulturalne scenarije (Kramsch 1998) po kojima razmišljamo i delujemo, jezik daje oblik mišljenju i supstanciju ponašanju. Vorf je tvrdio da "prirodu seciramo duž linija koje postavlja maternji jezik", dok Čomski veruje da maternji jezik samo daje „nazive urođenim univerzalnim konceptima“ (prema Wierzbicka 1997). Šta je starije - mišljenje ili jezik i u kom stepenu ljudska priroda i kultura, pojedinačno ili u interakciji oblikuju jezik - i dalje je predmet neslaganja.

Jasno je, ipak, da se fizička stvarnost mora odražavati u jeziku. Otuda ne čudi da arapski ima 255 reči za kamilu (Božović 1984: 8), a australski jezici niz reči za životinje koje svi drugi jezici označavaju kaojednu vrstu - kengura (Wierzbicka 1992: 8). Međutim, kategorizacija fizičke stvarnosti u znatnoj meri je uslovljena zadatim kulturalnim okvirom. Standardni prosečni evropski jezici (npr. engleski i srpski) u kontekstu situacije obavljanja svakodnevnog posla usredsređuje se na proces i rezultat ${ }^{3}$, a afrički jezici (npr. drogonski) na način izvršenja radnje (Heath/McPherson 2009). Poređenje evropske racionalističke i utilističke kulture sa linearnim konceptom vremena i uzročno-posledičnim razumevanjem odnosa sa afričkom kulturom cikličnog vremena i odnosa zasnovanih na magijskom i obrednom verovatno daje ključ razumevanja ovih razlika. Međutim, i jezici bliskih kultura pokazuju razlike u konceptualizaciji naizgled univerzalnih pojmova. Reč individualizam tako za Amerikance ima pozitivnu konotaciju slobode, kreativnosti i ličnog izražavanja, a za Francuze negativnu konotaciju egoizma, egocentrizma i samoće (Broady 2004: 69).

Ronovič (Ronowicz 1999) ukazuje na to da reči imaju dva značenja: prvo koje se navodi u rečnicima i definiše neutralno izvan socio-kulturalnog konteksta i drugo,

2 Termin prema Vorfu (Vorf 1979).

3 U engleskom se rezultat i proces iskazuju kroz markiranje aspekta: perfektivna i trajna vremena, a u srpskom derivacionim nastavcima. 
izvedeno značenje u kome socio-kulturalni kontekst daje dodatno specifično i često promenljivo značenje. Drugim rečima, kulture drugačije preslikavaju značenja naizgled sličnih reči (Broady 2004) uklapajući ih u drugačije strukturisane semantičke sisteme, koji pod uticajem društvene stvarnosti ne beleže samo osnovno značenje nego i njegova proširenja i sužavanja, prelazak iz referentnog u metaforično, simboličko i poetsko. Pripadnici određene kulturalne zajednice spontano prihvataju i usvajaju ova pomeranja kroz medije ili putem svakodnevnog opštenja, pa ova izvedena značenja stiču prikladnost, čime obezbeđuju legitimno mesto u kolektivnom repertoaru jezičke zajednice.

S druge strane, sistem obaveznih gramatičkih kategorija ima socio-kulturalne implikacije (Hill/Mannheim 1992). Sistem kategorija može, na primer, predstavljati temelj za određenu vrstu hegemonije ${ }^{4}$ (npr. muški i ženski rod imenica i zamenica, oslovljavanje u drugom licu). Iskazujući različite vremenske i prostorne odnose, različitu perspektivu kretanja, strukturu događaja i vrstu informacije (Jarvis 2011), govornici različitih jezika postavljaju okvir za drugačiji društveni fokus i kulturalnu praksu.

Međutim, u međukulturalnim poređenjima uočava se i obrnut uticaj budući da markiranje i učestalost pojedinih gramatičkih kategorija u datom jeziku mogu biti motivisani kulturom. Osećanja se u engleskom najčešće iskazuju pridevom i participom koji ukazuju na stanje, dok u slovenskim jezicima postoje posebni glagoli, prelazni i refleksivni, koji nose aktivno značenje. Vježbicka (Wierzbicka 1997) u ovome prepoznaje kulturalnu razliku između anglosaksonske kulture, koja ne odobrava nekontrolisano iskazivanje emocija, i ruske, koja iskazivanje emocija posmatra kao jednu od ključnih funkcija komunikacije. Učestalost deminutivnih oblika u ruskom, takođe, pokazuje društveno poželjno javno iskazivanje bliskosti, koje u germanskim kulturama i jezicima nije prikladno. Postojanje bezličnih konstrukcija sa dativom koji označava lice o kome se govori (npr. Dosadno mu je.), ili konstrukcija bez agensa (npr. Desilo se.), koje se javlja i u srpskom, a još češće u ruskom, ukazuje na osećanje ograničenosti individualne kontrole ili potčinjavanje nekoj nekontrolisanoj volji, tako različito od obaveznog isticanja vršioca radnje u angloameričkoj kulturi.

Upotreba jezika je sama po sebi vid kulturalnog ponašanja jer, u zavisnosti od situacionog i kulturalnog konteksta, jezik menja uloge i funkcije i vrednuje se u odnosu na druge komunikativne mogućnosti. Da li u određenoj situaciji u stranoj kulturi i na stranom jeziku uopšte treba nešto reći, ako treba, kada i kako? Kramš (Kramsch 2000: 25-26) daje primer američke studentkinje u Nemačkoj koja, kada je bila opomenuta da zatvori vrata sobe, nije mogla da proceni koji bi odgovor na tu opomenu govornicima nemačkog jezika bio najprikladniji u toj situaciji. Sličnim se pokazuje i potreba govornika srpskog jezika da pre obedovanja sebi i drugima poželi prijatan obrok formom „prijatno“. Engleskom govorniku ova vrsta konvencije je nepoznata i nepotrebna, pa svaki pokušaj da se prevede „prijatno", uglavnom, ne postiže željeni efekat.

Kulturom uslovljeno ponašanje manifestuje se i u pisanom jeziku. Konvencije pisanja u pojedinim žanrovima suštinski se razlikuju od jedne do druge kulture,

4 Posmatranje imenica muškog roda kao nemarkiranih sa obuhvatnim značenjem oba roda u poslednje vreme se često osporava kao primer muške dominacije u društvu, dok se tendencije zamene formalnog vi neformalnim ti posmatra kao dokaz težnji za demokratičnošću i jednakosti. 
od jednog do drugog jezika. Tako se npr. tvrdi da se esej u angloameričkom svetu razvija linearno, dok u ruskom jeziku i romanskim jezicima uključuje i delove koji ne doprinose linearnosti (Connor 2002: 494). Orijentalni jezici neguju indirektni prilaz, pa se u kineskom prvo uspostavlja veza sa klasičnim tekstovima, argumentacija se javlja oko sredine eseja, a teza se postavlja implicitno tek pri kraju (Yue 2009). Za razliku od zapadnih vrednosti individualnosti i originalnosti, vrednosti kojima teži kineski pisac je uspostavljanje dijaloga sa publikom i veze sa tradicijom, odnosno, umesto isticanja ličnih ideja javlja se "promovisanje socijalne harmonije i kohezije" (Yue 2009: 95).

Kako je rekao Sapir: „Svetovi u kojima različita društva žive su odvojeni svetovi, a ne samo isti svet sa pridodatim drugačijim nalepnicama" (prema Hill/Mannheim 1992: 385). Ako, dakle, želimo da uđemo u druge svetove učeći jezik, koji je najvažnije sredstvo socijalizacije, susrešćemo se sa drugačijom konceptualizacijom iskazanom kroz gramatičke kategorije i semantički sistem. Sintaksa, leksika i semantika stoje pod uticajem kulturalnog scenarija, a pragmatika i retorika nekog jezika teško se razumeju bez razumevanja šireg kulturalnog konteksta koji određuje očekivanja i granice prihvatljivosti. Drugim rečima, pravilan izbor jezičkih resursa u stranom jeziku i ispravno razumevanje nameravane poruke zavise od razumevanja dubljih slojeva ciljne kulture.

\section{KULTURALNI TRANSFER I JEZIČKA PRODUKCIJA}

Učeći strani jezik neizbežno se suočavamo sa stranom kulturom, pa se u procesu učenja osim međujezičkog uticaja javlja i međukulturalni uticaj. On se može pratiti dvosmerno.

Strani jezik ne prenosi samo strane reči nego i koncepte koji iza tih stranih reči stoje. U srpskom se u poslednje vreme uvrežio niz kolokacija koje su, u stvari, doslovan prevod sa engleskog (npr. suočiti se sa izazovom - u značenju: početi rešavati problem). Gledanje na problem ili prepreku kao na izazov duboko je usađeno u američkoj kulturi i implicira poziv na akciju i takmičenje (Kramsch 2000). 0staje pitanje da li se politički korektnom upotrebom jezika namerno prenose i politički korektni koncepti, ili se samo nekritičkim usvajanjem termina stvara jezik koji za većinu izvornih govornika nema ni referentnu ni metaforičku vrednost ${ }^{5}$. Kramš ukazuje na to da se fraze koje su ideološki nabijene, i pored toga što su leksički neprikladne, olako prenose u drugi jezik (Kramsch 2000: 43-44). Učenje stranog jezika, međutim, treba da pomogne u usvajanju obrazaca diskursa stranog jezika, ali i u objektivizaciji diskurzivne prakse na maternjem jeziku. Transfer ideoloških obrazaca (ako ideologiju posmatramo kao izraz projektovanih društvenih vrednosti date zajednice) iz ciljne kulture (K2) preko stranog jezika (L2) u izvornu kulturu (K1) doslovnim prevodom na maternji jezik (L1) nije potpun jer se ideološki markirane fraze smeštaju u neodgovorajuće kontekste i percipiraju na površinskom nivou. Drugim rečima, slabo razumevanje referentnog okvira i kulturalne

5 Nedavno je promovisan sajt za razotkrivanje korupcije pod imenom "Duvači u pištaljku“. Blow the whistle u engleskom znači razotkriti nekog u skrivenoj i nečasnoj radnji, ali u srpskom ovaj idiom nema metaforično značenje, nego, eventualno, asocira na političke događaje iz devedesetih godina prošlog veka. 
prakse ciljne kulture dovodi do ograničenog ili pogrešnog tumačenja poruke iz L2 i stvaranja tobožnjih ekvivalenata koji se u L1 ne mogu stvarno procesuirati. Iako se svaki iskaz u načelu može prevesti na drugi jezik, prevod iskaza koji je u L2 prirodan i lako se procesuira ima ograničen domet u L1 jer proizvodi nespretne iskaze (Hill/Mannheim 1992) koji se ne uklapaju u obrasce K1. Uočavanje kulturalne razlike blokirano je duboko ukorenjenim nesvesnim prihvatanjem naučenih kulturalnih pretpostavki kao univerzalnih.

$S$ druge strane, kulturalne pretpostavke iz $\mathrm{K} 1$ prenose se $\mathrm{U}$ L2 konceptualnim transferom (Jarvis 2011) i pragmatskim transferom. Konceptualne razlike i obrasci konceptualizacije usvojeni u jednom jeziku, koje mogu biti određene kulturom, utiču na korišćenje drugog jezika (Bylund/Jarvis 2011), a izbor jezičkih sredstava i strategija u realizaciji govornog čina i razumevanje kontekstualnih faktora i varijacija razlikuju se od kulture do kulture (Kasper/Schmidt 1996). K1 kulturalni okvir utiče na L2 jezičko ponašanje, pa su greške u upotrebi reči i gramatičkih kategorija i nedoumice oko iskazivanja različitih jezičkih funkcija u stranom jeziku, u stvari, pre posledica kulturalnog nego jezičkog transfera.

Zanimljiv primer uticaja budističke kulture na produkciju engleskog jezika kao L2 daje Tan (Tan 2005: 130). L1 tajlanđanski govornici engleskog obično koriste reč merit (srp. zasluga) u kolokaciji sa make (srp. napraviti) odražavajući koncept karme („ako činiš dobro, dobro ti se vraća“), dok, u skladu sa konceptom saosećanja sa drugima i nenarušavanja unutrašnje ravnoteže sukobom ili konfliktom, izbegavaju korišćenje poznatih jezičkih resursa (npr. never mind srp. nije važno, nema veze) za iskazivanje besa ili ironije. Naglašavanje osećanja pripadnosti tipično za kolektivističke kulture navodi L1 govornike nekih azijskih jezika da zamenicu "moj" zamenjuju sa "naš" (npr. naša kuća, naša zemlja, naš nastavnik) iako kontekst u stranom jeziku zahteva "moj" (Beishamayum 2010: 216).

Kulture različito definišu društvene situacije, kao i prikladnost resursa u datoj situaciji (Richards/Sukwiwat 1992). U Engleskoj je uobičajeno da se na izlasku iz autobusa zahvali vozaču. Jednostavno "thank you" za L1 srpskog govornika ne izgleda prikladno, ili makar uobičajeno, u datoj situaciji. Različito razumevanje faktora društvene moći i distance, ličnog integriteta, ljubaznosti i pristojnosti verovatno deluju na prekomernu upotrebu must (srp. morati) u obraćanju u drugom licu uočljivu kod L1 srpskih govornika engleskog.

Kulture se razlikuju po stilu komunikacije - od oslovljavanja, preko pozdravljanja, upoznavanja, tema razgovora, nivoa formalnosti do pravila interakcije i neverbalnog jezika. Na englesko "How do you do?" odgovara se takođe pitanjem, a na arapsko višeminutno propitivanje o zdravlju, porodici i opštem stanju, zahvaljivanjem bogu, klimanjem glave i stavljanjem ruke na srce. L1 srpski govornik lako će naučiti funkcionalni jezik u oba slučaja, ali će problem predstavljati neophodnost svesnog potiskivanja sopstvenog kulturalnog obrasca.

Kulturalna različitost prenosi se i u pismenu formu. U istraživanjima koja su obuhvatila univerzitetske nastavnike u Južnoj Koreji i Australiji pokazalo se da su Koreanci izražavali nelagodnost zbog suviše direktnog stila i nedostatka poštovanja australijskih kolega u elektronskoj komunikaciji, dok su Australijanci smatrali poruke Koreanaca preopširnim i zamerali im što izbegavaju odgovore na konkretna pitanja 
(Murphy/Levy 2006). Kramš ukazuje na problem francuskih naučnika koji, ako žele da objavljuju na engleskom, moraju da promene naučni stil uobičajen u njihovoj kulturi (Kramsch 1998: 62-63). Ni u jednom ni u drugom slučaju ne radi se o nedovoljnoj jezičkoj kompetenciji, nego se potvrđuje da se „lingvističko i kulturalno znanje izgrađuje jedno kroz drugo" (Watson-Gegeo 2004: 339) i zato zajedno i prenose. Intenzivan prenos drugačije retoričke tradicije u strani jezik može usloviti razvodnjavanje uobičajenih standarda u specifičnom kontekstu, kao što pokazuju primeri dokumenata u institucijama Evropske unije koji nagoveštavaju stvaranje neke nove „evroretorike" (Connor 2002: 505).

Po analogiji sa jezičkim transferom mogli bismo govoriti o kulturalnoj interferenciji koja može da ima i pozitivan i negativan efekat u učenju jezika. „Sopstvena kultura daje nam sočivo kroz koje gledamo svet, logiku kojom ga uređujemo i gramatiku koja svemu tome daje smisao" (Avruch/Black 1993, prema DuPraw/Axner). Kontakt sa drugom kulturom, prema tome, zahteva promenu dioptrije, odnosno sposobnost sagledavanja realnosti iz različitih perspektiva i prihvatanje raznovrsnih modela konceptualne organizacije i načina percepcije u usvajanju jezičkih formi, modela ponašanja, vrednosti, uverenja i obavljanju komunikativnih aktivnosti (Alpetkin 2010). Jezički i kulturalni transfer dešavaju se spontano i ne uvek pravilno, a sposobnost prekopčavanja iz sveta određenih jezički i kulturalno specifičnih normi i konvencija u drugi i nazad u prvi ili treći, siguran je znak razvoja jezički i kulturalno kompetentnog govornika.

\section{RAZVOJ JEZIČKIH I KULTURALNIH KOMPETENCIJA}

Primećeno je da multilingvali razvijaju višestruku kompetenciju (Cook 2003) koja u kontinuumu razdvajanja, povezivanja i spajanja dva ili više jezika kod istog govornika omogućava snalaženje pri različitim upotrebama jezika, omogućava razvoj kognitivnih sposobnosti i proces usvajanja kako različitih tako i sličnih ili istih odnosa, sadržaja i formi. Kultura, čije učenje traje čitav život, međutim, deluje na više nivoa i predstavlja fluidniji fenomen od jezika. Pojedinac istovremeno pripada različitim društvenim grupama kroz koje definiše sopstveni identitet i izgrađuje ličnu kulturu. Otuda je multikulturalnost, iako ne na svesnom nivou, uobičajena. Višestruka kompetencija je, svakako, neophodna da bi se takva multikulturalnost funkcionalno održala. Učenje stranih jezika treba da pomogne u stvaranju „delotvornih komunikatora i društvenih aktera u nizu različitih multilingvalnih i multikulturalnih konteksta" (Kirsch 2008: 15), odnosno da uporedo razvija lingvističku i sociokulturalnu kompetenciju kao deo širih sposobnosti u okviru opšteg obrazovanja.

„Usvajanje stranog jezika predstavlja usvajanje kulturalnih praksi i uverenja koje taj jezik otelovljuje u specifičnoj društvenoj grupi. Ono takođe relativizuje ono što učeniku izgleda kao prirodan jezik sopstvenih identiteta i približava ga shvatanju da su oni kulturalno i društveno konstruisani" (Byram 1997: 22). Prethodni primeri različite konceptualizacije i društvenih odnosa iskazanih kroz jezike i načini kako se oni prenose iz jednog u drugi jezik pokazuju da su jezik i kultura konvencije čije je prihvatanje važan deo socijalizacije i neraskidiv deo društvenog ponašanja. Jasno je da nije moguće naučiti sve međujezičke razlike i jasno je da u današnjem svetu komunikacija 
na stranom jeziku ne znači automatski komunikaciju sa izvornim govornikom ili tipičnim reprezentom ciljne kulture. Stoga je potrebno razvijati metode i pristupe u učenju stranog jezika, a ne samo koristiti gotove koncepte i stavove i nepromenjiva deklarativna znanja. Dakle, potrebno je razvijati neku vrstu stanja duha i intelektualne radoznalosti koja će iskustvo drugačijeg prihvatati kao proširenje identiteta i društveno poželjnu vrednost. Bajram (Byram 2010) u tom smislu podseća na nemačku tradiciju bildung, koja svrhu obrazovanja vidi u formiranju i transformaciji pojedinca, nasuprot utilističkom shvatanju učenja jezika kao marketinški kurentne robe na čiju vrednost utiču ekonomski ili politički razlozi (Kramsch 2005). Zajednički evropski okvir projektuje ulogu pojedinca kao društvenog agensa koji deluje u plurilingvalnom evropskom prostoru. Komunikacija u tom širem prostoru zavisi od "slaganja modela sveta i jezika" koje su učesnici u procesu internalizovali. Postajući plurilingvalan, učenik razvija interkulturalnost, ali i kompleksniju ličnost, kapacitete za učenje i otvorenost prema novim iskustvima (CEFR 2001). Društvena akcija i interkulturalni građanin zajedno prevladavaju opoziciju utilitarno - obrazovno. Drugim rečima, potrebno je naučiti jezičke elemente i načine njihove upotrebe da bi se omogućila komunikacija kojom se ostvaruju lični ili društveni ciljevi, ali je isto tako potrebno razumeti različite modele i razviti suptilniju mrežu kanala i sredstava za takvu komunikaciju.

To nas dovodi do konstrukta interkulturalne kompetencije, u kojem se presecaju jezik, kultura i komunikacija. U današnjoj nastavnoj praksi prihvaćen je komunikativni pristup kao način razvoja komunikativne kompetencije, koja osim jezičkog znanja podrazumeva veštine neophodne za artikulisanu i društveno prihvatljivu upotrebu jezika. Interkulturalna kompetencija ide jedan korak dalje objedinjujući stavove, znanja, veštine i vrednosti. Bajram (Byram et al. 2001; Byram et al. 2002) definiše interkulturalni stav kao otvorenost, radoznalost i spremnost na relativizaciju vrednosti, uverenja i ponašanja; znanje kao poznavanje društvenih procesa, proizvoda i grupa; veštine kao sposobnost tumačenja i povezivanja, otkrivanja i interakcije; dok vrednosti posmatra kroz kritičku kulturalnu svest, odnosno sposobnost vrednovanja fenomena u sopstvenoj kulturi i drugim kulturama.

Mogućnosti za razvoj interkulturalne kompetencije daje kritička pedagogija koja nastavni proces vidi kao dinamičan proces stvaranja (a ne prenošenja) znanja u kome su učenici neposredno angažovani u kreativnom kulturalnom razvoju (Byram/ Feng 2004). Polazeći od kritičkog vrednovanja pretpostavki i preispitivanja normi, ovaj pristup nastavi se usmerava na razvoj materijala koji upućuju na istraživanje pre nego što daju gotove informacije, odnosno na proces otkrivanja, analiziranja, poređenja, proživljavanja i povezivanja iskustva pre nego na same činjenice. Umesto finalnog proizvoda, cilj je sticanje sposobnosti kontinuiranog razvoja.

Uloga nastavnika je da razvija svest da je svaki međujezički kontakt istovremeno $i$ međukulturalni, da je interakcija iskustvo koje, da bi obogatilo učesnike ili im omogućilo ostvarenje cilja, zahteva i kulturalnu i jezičku kompetenciju. Nastavnik kroz dijalog i razmenu iskustava, osećanja i mišljenja stvara "treće mesto" u kome se iscrtava „treća perspektiva“" (Kramsch 2000: 210), odnosno kritički pogled i na L1/K1 i na L2/ $\mathrm{K} 2 \mathrm{u}$ prostoru u kome se drugačije percipira kao moguće, granice nesmetano prelaze, a identiteti relativizuju. 


\section{ZAKLJUČAK}

Istraživanja jezika kao „kognitivne, društvene i kulturalne prakse" (Kramsch 2004: 256) važna su za nastavu stranih jezika. Kompleksne psihološke i sociološke stvarnosti neposredno utiču na jezik koji se uči, kao i na onoga ko ga uči. Kako se te stvarnosti razlikuju, razlikuju se i načini na koji se uticaji manifestuju. Kultura daje okvir stvarnosti uobličenoj ljudskom delatnošću u kojoj jezik zauzima posebno mesto, pa je jezička pismenost nerazdvojiva od kulturalne. Zato učenje jezika, kulturalnih značenja i društvenog ponašanja jeste jedinstven proces u kome učenik treba da usvoji praksu koja će mu omogućiti uspešnu komunikaciju i funkcionisanje u hibridnom okruženju (Watson-Gegeo 2004). Promenjivo okruženje postavlja zahteve prevazilaženja tradicionalnih identiteta i ulaženja ispod slojeva pojavnosti u dublje slojeve značenja koji stoje u osnovijezika i kulture. Kako kultura daje naznake pre nego što otkriva, učenje zahteva spremnost na promenu, prihvatanje drugačijeg i podnošenje neizvesnosti. Povezujući polje kulture, jezika i komunikacije interkulturalna kompetencija, čiji razvoj obuhvata i kognitivni i afektivni domen, počiva na otvorenosti i kritičnosti, na sposobnosti razdvajanja, kombinovanja i spajanja i predstavlja polazište za kreativno generisanje novih znanja čija dinamika razvoja prati dinamiku promena u svetu. Ovako shvaćeno učenje jezika otuda prevazilazi svrhu samo vladanja određenim jezikom i postaje individualna i društvena potreba par excellence vremena u kome živimo.

\section{LITERATURA}

Alptekin, C. 2010. Redefining multicompetence for bilingualism and ELF. International Journal of Applied Linguistics 20, 1, 95-111.

Beishamayum, S. 2010. Difficulties faced by Manipurispeakers due to cultural differences in learning English. MJAL 2:3, 210-222.

Božović, R. 1984. Udžbenik arapskog jezika. Sarajevo: Svjetlost.

Broady, E. 2004. Sameness and difference: the challenge of culture in language teaching. Language Learning Journal 29, 68-72.

Bylund, E. \& S. Jarvis. 2011. L2 effects on L1 event conceptualization. Bilingualism: Language and Cognition 14 (1), 47-59.

Byram, M. 1997. Teaching and Assessing Intercultural Communicative Competence. Clevedon: Multilingual Matters.

Byram, M. 2010. Linguistic and Cultural Education for Bildung and Citizenship. The Modern Language Journal 94, ii, 317-321.

Byram, M., A. Nichols \& D. Stevens. 2001. Developing Intercultural Competence in Practice. Clevedon: Multilingual Matters.

Byram, M., B. Gribkova \& H. Starkey. 2002. Developing the Intercultural Dimension in Language Teaching. Strasbourg: Council of Europe.

Byram, M. \& A. Feng. 2004. Culture and language learning: teaching, research and scholarship. Language teaching 37 (3), 149-168.

Common European Framework of Reference for Languages: Learning, teaching, assessment. 2001. Cambridge: CUP. 
Connor, U. 2002. New Directions in Contrastive Rhetoric. TESOL Quarterly 36, 4, 493-510. Cook, V. J. 2003. Changing L1 in the L2 User's Mind. U V.J. Cook (ur.) Effects of the second language on the first. Clevedon: Multilingual Matters Ltd, 1-18.

DuPraw, M. \& M. Axner M. 2011. Working on Common Cross-cultural Communication Challenges. [Internet]. Dostupno na: http://www.wwcd.org/action/AMPU/crosscult. html [28.05.2011].

Geertz, C. 1973. The Interpretations of Cultures. New York: Basic Books.

Heath, J. \& L. McPherson. 2009. Cognitive Set and Lexical Strategies in Dogon Action Verb. Anthropological Linguistics 51, 1, 38-63.

Hill, J. \& B. Manheim. 1992. Language and World View. Annual Review of Anthropology 21, 381-406.

Hofstede, G., G. J. Hofstede \& M. Minkov. 2010. Cultures and Organizations: Software of the Mind - Intercultural Cooperation and its Importance for Survival. New York: The McGraw-Hill Co.

Jarvis, S. 2011. Conceptual transfer: Crosslinguistic effects in categorization and construal. Bilingualism: Language and Cognition 14(1), 1-8.

Kasper, G. \& R. Schmidt. 1996. Developmental Issues in IL Pragmatics. SSLA 18, 149-169.

Kirsch, C. 2008. Developing intercultural competence. Link 38, 15-18.

Kramsch, C. 1998. Language and Culture. Oxford: OUP.

Kramsch, C. 2000. Context and Culture in Language Teaching. Oxford: 0UP.

Kramsch, C. 2004. Language, Thought and Culture. U A. Davies i C. Elder (ur.) Handbook of Applied Linguistics. 0xford: Blackwell, 235-261.

Kramsch, C. 2005. Post 9/11: Foreign Languages between Knowledge and Power. Applied Linguistics 26/4, 545-567.

Murphy, M. \& M. Levy. 2006. Politeness in Intercultural Email Communication. Journal of Intercultural Communication 12. [Internet]. Dostupno na: http://www.immi.se/jicc/ index.php/jicc/article/view/96/65 [09.05.2011].

Richards, J. \& M. Sukwiwat. 1982. Language Transfer and Conversational Competence. Applied Linguistics 4, 2, 113-125.

Ronowicz, E. \& C. Yallop (ur.). 1999. English: one language, different cultures. London: Cassel.

Tan, M. 2005. Authentic language or language errors? Lessons from a learner corpus. ELT Journal 59/2, 126-134.

Vorf, B.L. 1979. Jezik, misao i stvarnost. Beograd: BIGZ

Watson-Gegeo, K.A. 2004. Mind, Language and Epistemology: Toward a Language Socialization Paradigm for SLA. The Modern Language Journal 88,iii, 331-350.

Wierzbicka, A. 1992. Semantics, Culture, and Cognition: Universal Human Concepts in Culture-Specific Configurations. Cary, NC: OUP.

Wierzbicka, A. 1997. Understanding Cultures through Their Key Words: English, Russian, Polish, German, and Japanese. Cary, NC: OUP.

Yue, Y. 2009. Rhetoric: A Tale of Two Cultures. The International Journal of Language, Society and Culture 28, 92-99. 


\section{SUMMARY}

\section{CULTURE AND FOREIGN LANGUAGE LEARNING}

The paper focuses on the relationship between language and culture and the importance it has for a successful foreign language teaching and learning. The examples from several languages are presented to demonstrate the differences in conceptualization and realization of language patterns and the interdependence of linguistic items and cultural models. The firm link between culture and language on the one hand, and the differences between not only L1 and L2, but also between target and native cultures on the other hand, provide for cultural transfer to affect linguistic behaviour, thus necessitating transformation of foreign language learning into a process of simultaneous differentiation and acquisition of both linguistic and cultural practices. Integration of linguistic, cultural and communicative perspectives for the purpose of learning the desired behaviour embedded in communication activities is a part of the development of intercultural competence, which, as comprising attitudes, knowledge, skills and values, should enable communicators to act as culturally aware social agents in multilingual and multicultural environments.

KEYWORDS: culture, language, transfer, behaviour, practice, communication, intercultural competence.

(Originalan naučni rad primljen 20.01.2012;

ispravljen 31.10.2012;

prihvaćen 01.11.2012) 